\title{
High Strength Mg-5Sn Alloy Prepared by Rapidly Solidified Powder Metallurgy
}

\author{
Zhi-Ming CUI ${ }^{1, a}$, Yun-Gui CHEN ${ }^{2, b,{ }^{*}}$, Wu-Cheng DING ${ }^{2, \mathrm{c}}$, Chun-Ming WANG ${ }^{2, \mathrm{~d}}$, \\ Su-Fen $\mathrm{XIAO}^{2, \mathrm{e}}$ and Peng $\mathrm{CHENG}^{1, \mathrm{f}}$
}

\author{
${ }^{1}$ School of Aeronautics and Astronautics, Sichuan University, Chengdu 610065, China \\ ${ }^{2}$ College of Materials Science and Engineering, Sichuan University, Chengdu 610065, China \\ azhimingcui@stu.scu.edu.cn, bygchen60@aliyun.cn, cdwc20150520@163.com,

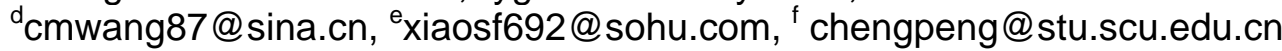

'ygchen60@aliyun.cn

Keywords: Mg-Sn alloy, Rapid solidification, Powder metallurgy, Microstructure, Mechanical properties

\begin{abstract}
The microstructure and mechanical properties of rapidly solidified powder metallurgy Mg-5Sn alloy were studied in this paper. The results show the nano-scale $\mathrm{Mg}_{2} \mathrm{Sn}$ phases are dispersed homogeneously in the fine $\alpha$-Mg matrix for the RS P/M Mg-5Sn alloy. In addition, it is also found that the submicron structure appears in the $\mathrm{Mg}$ matrix of $\mathrm{RS} \mathrm{P} / \mathrm{M}$ alloy. The tensile strength, yield strength and elongation are 342.8 $\mathrm{MPa}$, 337.5 $\mathrm{MPa}$ and 6.5\%, respectively, which increases correspondingly by $215.4 \%, 752.3 \%$ and decreases by $9.7 \%$ in comparison with that of the as-cast Mg-5Sn alloy, and the tensile fracture is obvious dimples.
\end{abstract}

\section{Introduction}

Magnesium-based alloys, as the lightest structural metal materials, are widely used in many engineering areas due to high specific strength, good damping properties, and excellent thermal and electrical conductivity [1-4]. However, because of their low tensile and yield strength which is difficult to meet the requirement of high-performance parts or components, the practical use of magnesium alloys are still far less than that of aluminum alloys. So, it has great significance to research and develop high strength magnesium alloys. While the strength of magnesium alloys prepared by traditional methods are not high enough, or they contain a lot of expensive rare earth elements, more and more attentions are paid to new materials preparation technologies [5]. The rapidly solidification (RS) processing yields structural modification such as reduction of segregation, grain refinement, increasing solid solubility and the formation of non-equilibrium phases, which got outstanding performance [6-8]. As a unique material preparation technology, the RS powder metallurgy (P/M) technology can obtain matrix of super fine grain and dispersing nano-sized precipitated phases and improve sharply the mechanical properties. The emergence of RS P/M technology opens a new road for the research and development of super-high strength magnesium alloys [8-9]. The RS P/M method have been investigated for magnesium alloys, resulting in remarkable improvement in strength [10-14].

At present, the RS powders are usually prepared by atomization method [10]. In this paper, the RS powders are prepared by RS ribbons and high energy ball milling. The cooling speed of the RS ribbons is higher than that of the atomization method. The difference of the saturation solid solubility of tin (Sn) in magnesium (Mg) at high temperature and low temperature is great, which benefit the RS processing. $\mathrm{Mg}_{2} \mathrm{Sn}$ phases are heat-resistant phases, and $\mathrm{Mg}-\mathrm{Sn}$ alloy is potential for applications at elevated temperatures [15-17], where Mg-5Sn alloy is the best [18]. It has no research of the RS P/M Mg-Sn alloys until now. The aim of the paper is to investigate the microstructure and mechanical properties of RS P/M Mg-5Sn binary alloy. 


\section{Experimental}

The Mg-5Sn alloy powders were prepared by the rapidly solidified (RS) ribbons and high energy ball milling (SPEX 8000M). Firstly, the RS ribbons of Mg-5Sn alloy were prepared by a single-roller melt spinning at a circumferential speed of $20 \mathrm{~m} \cdot \mathrm{s}^{-1}$ under the protection of argon. The average thickness of the RS ribbons are $0.15 \mathrm{~mm}$. Secondly, the RS ribbons were cut into $2-3 \mathrm{~cm}$ and crushed by a high energy ball milling under argon protection. Finally, the alloy powders were acquired and sieved to less than $100 \mu \mathrm{m}$. The alloy powders were hot extruded to metal bars (diameter: $4 \mathrm{~mm}$ ) at $573 \mathrm{~K}$ by a hot extruding machine.

The metallographic specimens were polished and etched with a solution of 4 vol.\% nitric acid + ethyl alcohol. The microstructure and fracture analysis were observed with scanning electron microscope (SEM, JEOL, JSM-6490LV) and transmission electron microscopy (TEM, JEOL 2100F). Thin foils for TEM were prepared by ion-beam thinning technique at a voltage of $3.0 \mathrm{keV}$ and incident angle from $8^{\circ}$ to $4^{\circ}$. The overall phase structures of the test alloys were analyzed using $\mathrm{X}$-ray diffraction (XRD, Dan Dong Fang Yuan, DX-2006) with $\mathrm{Cu} \mathrm{K}_{\alpha}$ radiation. The tensile tests were conducted at room temperature on an electro-universal testing machine (Instron5569) with a crosshead speed of $2.4 \mathrm{~mm} \cdot \mathrm{min}^{-1}$.

\section{Results and Discussion}

Fig. 1 shows the XRD patterns of RS P/M and as-cast Mg-5Sn alloys. There are only $\alpha$-Mg (PDF: No. 35-0821) and $\mathrm{Mg}_{2} \mathrm{Sn}$ (PDF: No. 07-0274) phases in the RS P/M and as-cast Mg-5Sn alloys. The $\mathrm{Mg}_{2} \mathrm{Sn}$ phase diffraction peak intensities of the RS P/M alloy are higher than that of the as-cast alloy. The mass and volume fraction of the $\mathrm{Mg}_{2} \mathrm{Sn}$ phase is calculated by the Rietveld refinement, the mass and volume fraction of the $\mathrm{Mg}_{2} \mathrm{Sn}$ phases in the RS P/M alloy and as-cast Mg-5Sn alloy are 4.0 wt.\%, 2.0 vol.\%; and 1.9 wt.\%, 1.0 vol.\%, respectively. The content of $\mathrm{Mg}_{2} \mathrm{Sn}$ phases in the RS P/M alloy are more than that in the as-cast Mg-5Sn alloy.

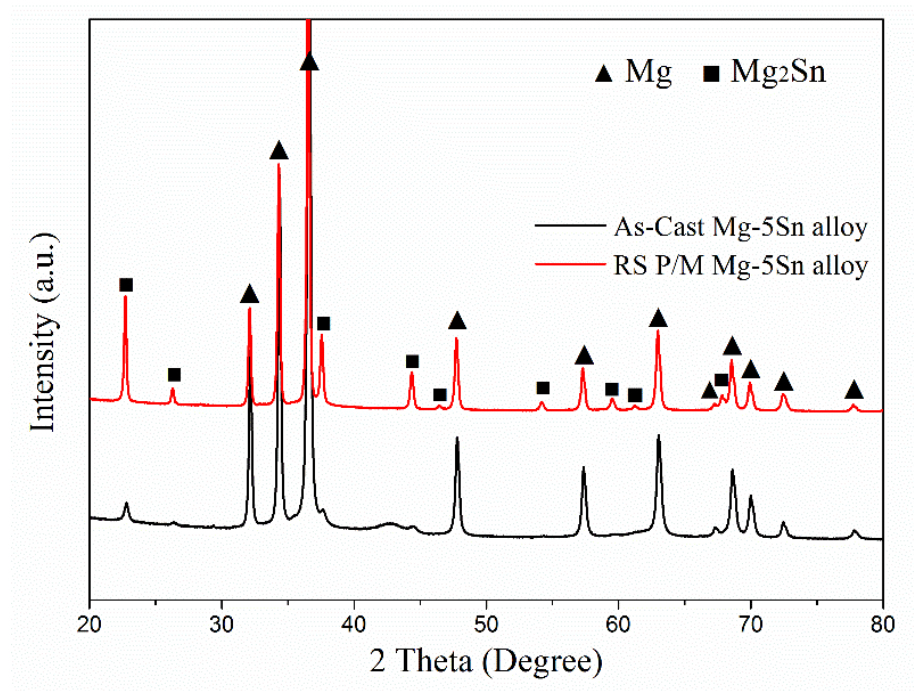

Fig. 1 XRD patterns of RS P/M and as-cast Mg-5Sn alloys

SEM micrographs of the RS P/M and as-cast alloys and TEM micrographs of the RS P/M alloy are shown in Fig. 2. It is found that there are the eutectic structure $\left(\alpha-\mathrm{Mg}+\mathrm{Mg}_{2} \mathrm{Sn}\right)$, devoiced eutectic $\mathrm{Mg}_{2} \mathrm{Sn}$, and second precipitated $\mathrm{Mg}_{2} \mathrm{Sn}$ in the as-cast Mg-5Sn alloy in Fig. 2(a) [18]. However, the RS P/M Mg-5Sn alloy is composed only of primary $\alpha$-Mg matrix and $\mathrm{Mg}_{2} \mathrm{Sn}$ particles dispersed equably, combined with Fig.1. The sizes of the $\mathrm{Mg}_{2} \mathrm{Sn}$ are 75 to $500 \mathrm{~nm}$ and the average size is about $187 \mathrm{~nm}$ in Fig. 2(c). The submicron structure appears in the Mg matrix of RS P/M alloy in Fig. 2(d) and the size is about $200 \mathrm{~nm}$. 

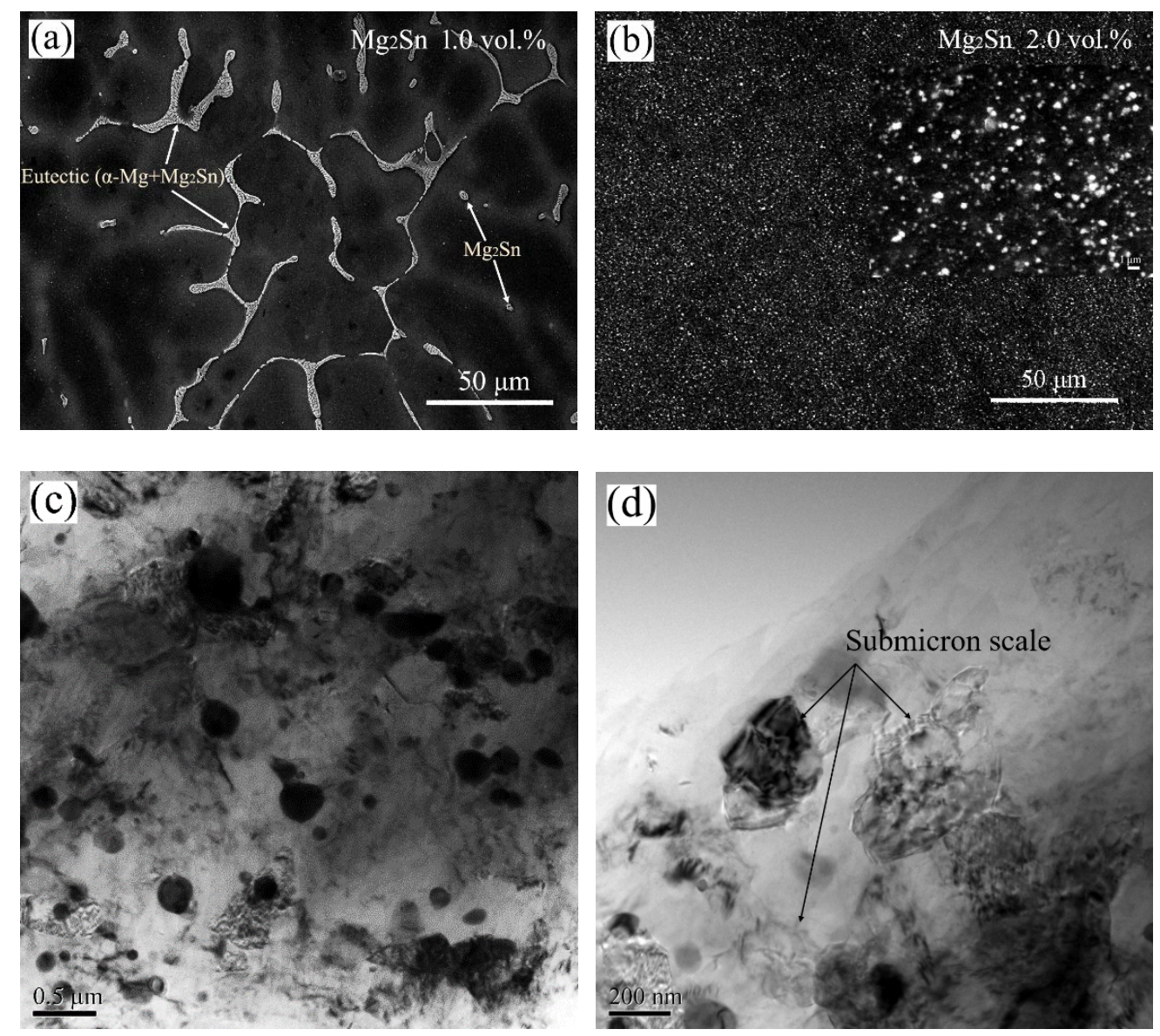

Fig. 2 SEM micrographs of the cast Mg-5Sn (a) and the RS P/M Mg-5Sn alloys (b), and TEM micrographs of the RS P/M Mg-5Sn alloy (c), (d)

Fig. 3 shows the stress-strain curve of the RS P/M and as-cast $\mathrm{Mg}-5 \mathrm{Sn}$ alloys at room temperature. It can be seen that the tensile strength, yield strength and elongation of RS P/M and as-cast Mg-5Sn alloys are 342.8 $\mathrm{MPa}$, 337.5 $\mathrm{MPa}, 6.5 \%$ and $108.7 \mathrm{MPa}$, 39.6 $\mathrm{MPa}, 7.2 \%$, respectively. Compared with the as-cast Mg-5Sn alloy, the tensile strength and yield strength of the RS P/M alloy increase obviously by $215.4 \%, 752.3 \%$, respectively, and the elongation decreases by $9.7 \%$.

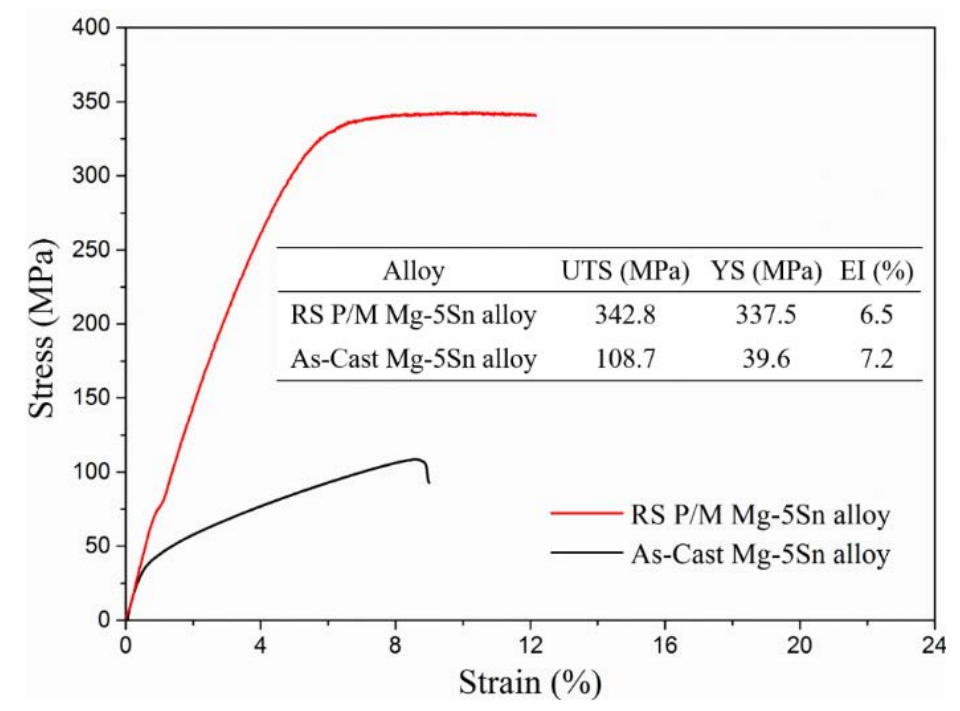

Fig. 3 Stress-strain curve of the RS P/M and as-cast Mg-5Sn alloys at room temperature 
Fig. 4 shows the SEM tensile fracture micrographs of the RS P/M and as-cast alloy at room temperature. The as-cast alloy shows quasi-cleavage fracture in Fig. 4 (a). Compared with the tensile fracture micrograph of the as-cast alloy, the obvious dimples can be found in the tensile fracture of the RS P/M alloy in Fig. 4 (b), which explains that the fracture mechanism is different. Samples with smaller grain sizes showed no uniform elongation and limited ductility [19]. Combined the decline of elongation in the RS P/M alloy and the transformation of the fracture mechanism, it is suggested that the grain size of the RS P/M alloy is abnormal finer.
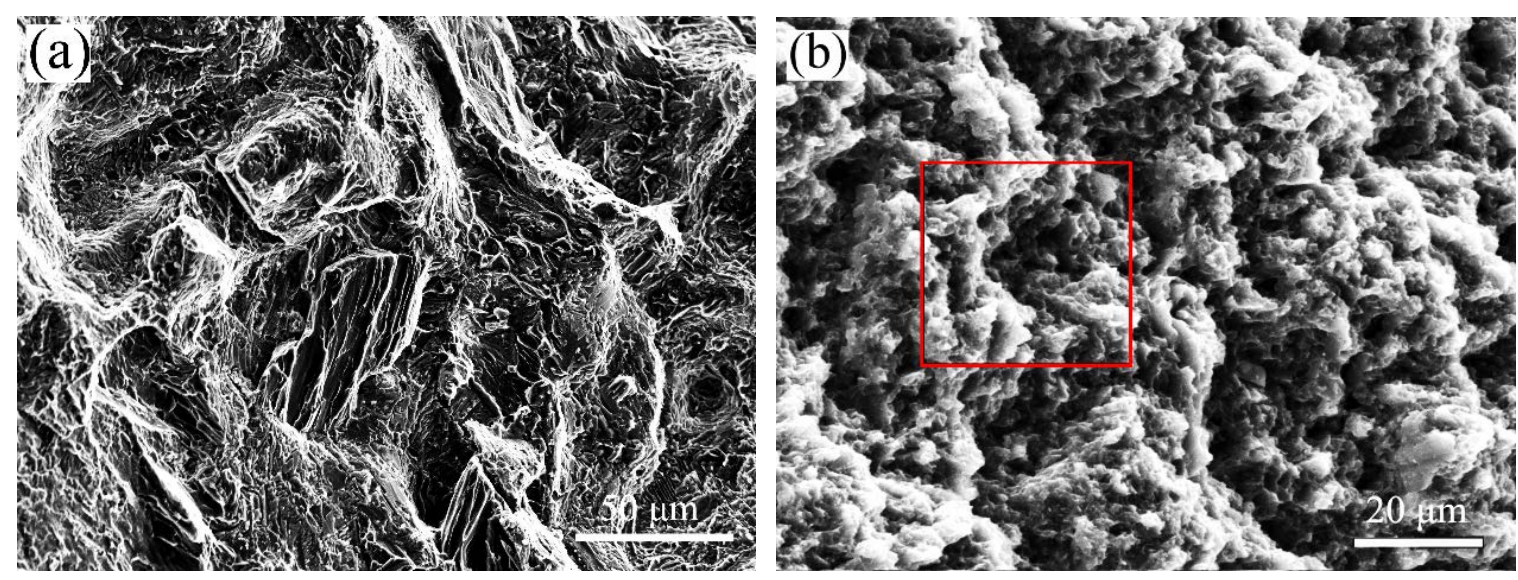

Fig. 4 SEM tensile fracture micrographs of the as-cast (a) and RS P/M Mg-5Sn (b) alloys at room temperature

The existent form and distribution of the alloying element in the metal matrix decide its role. The quantity of $\mathrm{Mg}_{2} \mathrm{Sn}$ phases in the RS P/M alloy are obviously more than that in the as-cast alloy, and the $\mathrm{Mg}_{2} \mathrm{Sn}$ particles are finer and distributed homogeneously, as shown in Fig. 1 and Fig. 2(a \& b). On the basis of Orowan theory, the strength is inversely proportional to the distance between precipitates and directly proportional to the second phase particle size, so the dispersion strengthening effect is stronger than that in the as-cast alloy. The grain size of the RS P/M alloy is finer than that of the as-cast alloy. According to the refinement and Hall-Petch equation, the refinement strengthening effect is stronger than that in as-cast alloy, especially for the increase of the yield strength. The submicron structure appears in the RS P/M alloy which may enhance the strength, as shown in Fig. 2 (d). The sharp increase of tensile strength and yield strength may be a comprehensive effect of fine dispersed $\mathrm{Mg}_{2} \mathrm{Sn}$ phase strengthening, $\alpha$-Mg fine-grained strengthening and submicron scale strengthening in the $\alpha-\mathrm{Mg}$ matrix.

\section{Summary}

The rapidly solidified powder metallurgy (RS P/M) processing improve the microstructure of the Mg-5Sn alloy, resulting in finer (about $187 \mathrm{~nm}$ ) and uniformly distributed $\mathrm{Mg}_{2} \mathrm{Sn}$, finer $\alpha$-Mg grains and submicron structure (about $200 \mathrm{~nm}$ ), compared with that of as-cast Mg-5Sn alloy. The tensile strength, yield strength and elongation of RS P/M Mg-5Sn alloy are 342.8MPa, 337.5MPa and $6.5 \%$, respectively. Compared with the as-cast alloy, the tensile strength and yield strength increase by $215.4 \%$ and $752.3 \%$, respectively, and the elongation decreases by $9.3 \%$.

\section{References}

[1] B.L. Mordike, T. Ebert, Magnesium: properties-applications-potential, Mater. Sci. Eng., A 302 (2001) 37-45.

[2] H. Friedrich, S. Schumann, Research for a "new age of magnesium" in the automotive industry, J. Mater. Process. Tech. 117 (2001) 276-281.

[3] G.Y. Yuan, Z.L. Liu, Q.D. Wang, W.J. Ding, Microstructure refinement of Mg-Al-Zn-Si alloys, 
Mater. Lett. 56 (2002) 53-58.

[4] C.M. Wang, Z.M. Cui, H.M. Liu, Y.G. Chen, W.C. Ding, S.F. Xiao, Electrical and thermal conductivity in Mg-5Sn alloy at different aging status, Mater. Design 84 (2015) 48-52.

[5] K. Hono, C.L. Mendis, T.T. Sasaki, K. Oh-Ishi, Towards the development of heat-treatable high-strength wrought Mg alloys, Scripta Mater. 63 (2010) 710-715.

[6] H.J. Zhang, D.F. Zhang, C.H. Ma, S.F. Guo, Improving mechanical properties and corrosion resistance of Mg-6Zn-Mn magnesium alloy by rapid solidification, Mater. Lett. 92 (2013) 45-48.

[7] B.H. Kear, Rapid Solidification Technology, National Academy Press, Cutting Edge Technologies, (1984) 86-108.

[8] E. Ayman, U. Junko, K. Katsuyoshi, Application of rapid solidification powder metallurgy to the fabrication of high-strength, high-ductility Mg-Al-Zn-Ca-La alloy through hot extrusion, Acta Mater. 59 (2011) 273-282.

[9] E. Mora, G. Garcés, E. Oñorbe, P. Pérez, P. Adeva, High-strength Mg-Zn-Y alloys produced by powder metallurgy, Scripta Mater. 60 (2009) 776-779.

[10] Y. Kawamura, K Hayashi, A. Inoue, Rapidly Solidified Powder Metallurgy Mg97Zn1Y2Alloys with Excellent Tensile Yield Strength above 600 MPa, Mater. Trans. 42 (2001) 1171-1174.

[11] Y.F. Zhao, J.J. Si, J.G. Song, X.D. Hui, High strength Mg-Zn-Ca alloys prepared by atomization and hot pressing process, Mater. Lett. 118 (2014) 55-58.

[12] Z.Y. Zhang, H.S. Yu, S.Q. Wang, H.T. Wang, G.H. Min, Microstructure and tensile properties of ZK60 alloy fabricated by simplified rapid solidification powder metallurgy (S-RS P/M) process, J. Mater. Sci. Technol. 26 (2010) 151-155.

[13] A. Elsayed, K. Kondoh, H. Imai, J. Umeda, Microstructure and mechanical properties of hot extruded $\mathrm{Mg}-\mathrm{Al}-\mathrm{Mn}-\mathrm{Ca}$ alloy produced by rapid solidification powder metallurgy, Mater. Design 31 (2010) 2444-2453.

[14] M. Sugamata, S. Hanawa, J. Kaneko, Structures and mechanical properties of rapidly solidified Mg-Y based alloys, Mater. Sci. Eng., A 226 (1997) 861-866.

[15] N. Hort, Y. Huang, T. Abu Leil, P. Maier andK. U. Kainer, Microstructural Investigations of the Mg $\quad$ y $\quad$ Stem, $x$ (2006) 359-364.

[16] C.L. Mendis, C.J. Bettles, M.A. Gibson, C.R. Hutchinson, An enhanced age hardening response in Mg-Sn based alloys containing Zn, Mater. Sci. Eng., A 435 (2006) 163-171.

[17] T.T. Sasaki, K. Oh-Ishi, T. Ohkubo, K. Hono, Enhanced age hardening response by the addition of Zn in Mg-Sn alloys, Scripta Mater. 55 (2006) 251-254.

[18] H.M. Liu, Y.G. Chen, Y.B. Tang, S.H. Wei, G. Niu, The microstructure, tensile properties, and creep behavior of as-cast Mg-(1-10)\% Sn alloys, J. Alloy. Compd. 440 (2007) 122-126.

[19] J.S. Hayes, R. Keyte, P.B. Prangnell, Effect of grain size on tensile behaviour of a submicron grained Al-3 wt-\% Mg alloy produced by severe deformation, Mater. Sci. Tech. 16 (2000) 1259-1263. 